\title{
Training of Health Workers in Côte d'Ivoire: The Socio Anthropological Approach in Public Health Interventions
}

\author{
Adou Serge Judicael ANOUA* \\ Department of Anthropology and Sociology, Alassane Ouattara University, Côte d'Ivoire, BP V18 Bouaké 01
}

*Corresponding Author: Adou Serge Judicael ANOUA, Department of Anthropology and Sociology, Alassane Ouattara University, Côte d'Ivoire, BP V18 Bouaké 01

\begin{abstract}
The public health problems in Côte d'Ivoire are multiple and complex. The epidemiological transition is struggling to begin. However, the national health system in place tends to give primacy to curative medicine. In the process of finding solutions, the biomedical dimension remains privileged. We conclude that in Côte d'Ivoire, the national public health system is highly medicalized. And yet, not all health problems have a vaccine. As a result, how can the burden of disease in the country be reduced? How to get the vast majority of the population to benefit from a sustainable health? In response to these questions, we suggest that the relevant assumption for sustainable health for the entire population is the establishment of a nursing education system rooted in health and culture. It is a question of orienting the nursing care on medical knowledge and the knowledge of the social and cultural environment of the users. Thus, socioanthropology as a social science enters the training cycle of nursing at the National Institute of Training of Health Agents of Bouake. Despite the slow progress in integrating socio-anthropology into the Ivorian health system, it is important to hope that in the near future this challenge will be met. The added value expected of her in the hospital environment appears equally important. It is envisaged by the training of health workers in this field, the awareness of the immersion of the living environment, adherence to treatment by the patient, cultural relativism by the health worker, dynamic patient management and close collaboration between medical and social scientists and humanities as a guarantee of effectiveness.
\end{abstract}

Keywords: Nursing; Health Worker Skills; Socio-Anthropology; Public Health;Health Education.

\section{INTRODUCTION}

The public health problems in Côte d'Ivoire are multiple and complex. Multiple because all the actors of the health are concerned: parasitic and infectious diseases, the question of mental health, the so-called chronic diseases and the problems of maternal and infant health appear to be of great concern to each other (EDS- MICS, 2011-2012) [1]. These health problems also appear to be complex, especially as each of the categories indicated is at the intersection of a variety of biological, environmental, socioeconomic, demographic, political, social and cultural factors. In light of this gloomy picture, the national health system in place tends to give primacy to curative medicine. Prevention remains essentially reduced to chemoprophylaxis. This means that in the process of finding solutions, the biomedical dimension remains privileged to the detriment of socio-anthropological aspects. We deduce that in Côte d'Ivoire, the national public health system is highly medicalized. And yet, all the indicated health problems do not have a vaccine.
As a result, questions arise. How to reduce this burden of disease? And how can the vast majority of the population benefit from sustainable health?

\section{INTERVENTION}

In response to these questions, we suggest that the relevant assumption for sustainable health for the entire population is the establishment of a nursing education system rooted in health and culture. It is a question of orienting the nursing care on medical knowledge and the knowledge of the social and cultural environment of the users. Thus, in 2016, socio-anthropology as a social science enters the training cycle of nursing at the National Institute of Training of Health Agents of Bouaké. This is an introductory course in the anthropology of health. The level of study concerned is all nursing, midwifery and nursery students in the first year of the cycle. They are trained in theory and practice to achieve shared caregiver-patient satisfaction in the dynamics of nursing. The 
objective is to show to what extent socioanthropology can support nursing care.

\section{RESULTS}

The quest for good health for the population requires the establishment of an integrated culture of nursing. This concept of integrated culture is first understood as a concept based on values, knowledge and local know-how beneficial to human health, then as a dynamic process of lifelong health education that directs health workers to appropriate and effective care habits. From this notion, the training of the health worker revolves around the knowledge of health and disease-related belief systems and socio-anthropology in the skills of the health worker.

\subsection{Knowledge of Belief Systems Related to Health and Illness}

This theoretical component aims to teach health workers to identify social representations, attitudes and practices related to health and illness. Clearly today, health and culture are related facts. Culture is a factor influencing the health and management of patients (Vega A., 2001) [2]. Indeed, for every given community, anybody modification is not necessarily synonymous with illness. There is in no way a term of correspondence between the system of the senses and the system of signs of the disease when passing from one culture to another. The system of senses, that is, the models of explanation of diseases, vary from one cultural group to another (Massé R., 1995) [3]. This leads to the conclusion that the evaluation criteria of normal and pathological are by no means universal. This is the example of diarrhea in children in Baoulé country which is not considered as a disease. According to this group, this state of morbidity is a developmental logic of this child. In another case, goitre among Yacouba is not always considered as a disease, it is instead seen as a sign of beauty. This constant change in the threshold of normality is due to the variation of belief systems and value systems. From this relativity of the normal and pathological, it follows from different perceptions, attitudes and practices on the notion of health and disease in the human species.

It is from the anthropological approach that it will be possible to highlight, the systems of perception, of belief in the gravity or not of the disease, the status of the patient or not, the gender roles, the ethics dimension of the health problem posed, the adhesion and / or participation of the populations concerned, the matrices of openness or resistance to the promotion of health. Indeed, the absence of socio-anthropology in the practice of nursing in Côte d'Ivoire, shows the negation of the impact of culture on public health problems or simply, risk behaviors such as causal factors of public health problems. How can this care be effective if it deals only with the pathology by ignoring the patient? This is the foundation of the issues of socio-anthropology in the skills of the health worker.

\subsection{Socio-Anthropology in the Skills of the Health Worker}

This practical component consists in indicating to the health workers how to deal with the various attitudes of users. In the process of the therapeutic relationship, adherence to treatment by the patient and environmental sanitation by the health worker are the basic principles for quality management. At the end of this process, satisfaction is shared by both parties; that is, the caregiver and the patient. In order to achieve this final objective, the care provided by the health worker remains initially centered on the patient and not on the pathology (Jodelet, D., 2006) [4]. These principles governing the caregiver-patient relationship lead to indicate the place and role of socio-anthropology in nursing care.

\subsection{The Place of Socio-Anthropology in Nursing}

In the health worker's intervention, the central posture of the patient in the management process implies taking into account the following elements: the socio-cultural environment, the patient and the pathology. In the dynamics of patient management, it is clear that socio-anthropology is at the very beginning of this care. This is justified by the fact that at first contact for the diagnosis, the semiological discourse (the description of the signs or symptoms of the illness by the patient) reflects the reflection of the perceptions, suggests the forms of emotion and explicitly or not, the expectations of the patient. All these various elements inevitably find their source in the cultural reservoir of the patient. So to speak, these constitute the benchmarks from which the health worker gives meaning to his care. From a 
logical point of view, socio-anthropology is situated upstream of the medical sciences in the dynamics of patient care (Hudelson Patricia, 2008) [5]. This pedagogical expectation in the training of the health worker presupposes the acquisition of some anthropological theoretical elements in order to be able to penetrate the socio-cultural milieu of the patient with a view to a more effective and more relevant care. Can a child truly be cured of intestinal parasitosis if it is totally unknown in what hygienic conditions this child lives? Awareness about the immersion of the environment lifestyle is not enough. Ethical values matter.

\subsection{The Role of Socio-Anthropology in Nursing}

This role to be played by the health worker in his relationship with the patient is a challenge in relation with the fundamental concept of ethnocentrism. The implementation of ethnocentrism is to show that one's own culture or ethnicity is considered superior to that of others (Guillon-Legeay D., 2016) [6]. In our nursing context, it is not a question of demonstrating the superiority of scholarly medical knowledge over the social representations of the patients in front. On the contrary, the reflex to be developed by the health worker vis-à-vis his patients must be to fight against any value judgment whatever the level of education, physical appearance and forms of expression emotions in the anguish and suffering of his patients. Indeed, this attitude of serenity and thoughtfulness is an important objective element of the construction of the contract of trust with the patients, because, contrary to this ethnocentrism, there is cultural relativism which proclaims for its part that, "there is no higher culture, no lower culture, the cultures are only different "(BARREAU H., NATHAN T.) [7]. All patients should be examined with the same attention and availability. The educator's role as health worker underlies this doctrine of cultural relativism. This virtue is not limited to therapeutic education. It also takes into account all the risk factors of the patient's environment.

\section{CONClusion}

Socio-anthropology is both theoretical and practical. The mobilization of its theoretical and practical instruments in nursing care is an operation that leads to a relevant understanding of the health behaviors of individuals, groups and societies. As things stand at present, the application of this approach to the field of research alone is hardly sufficient in view of the worrying problem of the epidemiological transition in Côte d'Ivoire. This approach is invited in the clinic to speed up the process. Especially since health problems are not situations to be observed outside the sociocultural environment that underlies them. Human behavior is an essential underlying factor. Despite the slow progress in integrating socio-anthropology into the Ivorian health system, it is important to hope that in the very near future this challenge will be met. The training of health workers in this area leads to this conviction. The added value expected of her in the hospital environment appears equally important. On the other hand, looking for appropriate and effective solutions in the long term, requires a multidisciplinary essential framework. Close collaboration between the medical profession and the social and human sciences specialists is a guarantee of efficiency.

\section{REFERENCES}

[1] Ministère de la santé et de la lutte contre le sida (MSLS), l'institut national de la statistique (INS) et ICF international. (2012). Enquête Démographique et de Santé et à Indicateurs Multiples de Côte d'Ivoire 2011-2012 : Rapport préliminaire. [Côte d'Ivoire Demographic and Health Survey and Multiple Indicator Cluster Survey 2011-2012: Preliminary Report]. MSLS, INS et ICF International, Calverton, Maryland, USA, p. 1-561. Retrieved April11, 2019 from https://www.dhsprogram.com/ pubs/pdf/FR272/FR272.pdf.

[2] Vega, A.(2001). Soignants/soignés. Pour une approche anthropologique des soins infirmiers. [Caregivers/caregivers. For an anthropological approach to nursing].Paris, Bruxelles, De Boeck Université, collection « Savoirs \& santé », 160 p.

[3] Massé, R.(1995). Les apports de l'anthropologie à l'épidémiologie: le cas du rôle étiologique de l'isolement social.[The contributions of anthropology to epidemiology: the case of the etiological role of social isolation]. Revue Ruptures, revue transdisciplinaire en santé, 2(1), 102-117.

[4] Jodelet, D.(2006). Culture et pratiques de santé. [Health Culture and Practices].Nouvelle revue de psychosociologie, 1(1), 219-239. doi:10. 3917/nrp.001.0219.

[5] Hudelson, P.(2008). Que peut apporter l'anthropologie médicale à la pratique de la 
Training of Health Workers in Côte d'Ivoire: the Socio-Anthropological Approach in Public Health Interventions

médecine ? [What can medical anthropology bring to the practice of medicine?]. RevueMédecine et Hygiène, 2(2407), 35-39.

[6] Guillon-Legeay, D.(2016). Claude LéviStrauss. L'ethnocentrisme, entre humanité et barbarie, ou le paradoxe du relativisme culturel.
Classiques iPhilo, Retrieved April11, 2019 from http://iphilo.fr.

[7] Barreau,H., Nathan,T. RELATIVISME. Encyclopædia Universalis. Retrieved June 13, 2019 from http://www.universalis.fr/ encyclopedie/relativisme/

Citation: Adou Serge Judicael ANOUA, Training of Health Workers in Côte d'Ivoire: The Socio Anthropological Approach in Public Health Interventions. ARC Journal of Nursing and Healthcare. 2021; 7(1):01-04. DOI: doi.org/10.20431/2455-4324.0701001.

Copyright: () 2021 Authors. This is an open-access article distributed under the terms of the Creative Commons Attribution License, which permits unrestricted use, distribution, and reproduction in any medium, provided the original author and source are credited. 